\title{
A CASE OF PERIARTERITIS NODOSA WITH SUBCUTANEOUS LESIONS AND RECOVERY
}

\author{
BY \\ C. WILFRED VINING, M.D., F.R.C.P., D.P.H. \\ Professor of Children's Diseases, Leeds University.
}

Periarteritis nodosa is the name given to a disease with a high mortality affecting the arterial system, characterized by a widespread destructive nodular arteritis which produces, by interference with the blood supply from occlusion and thrombosis, a variable clinical picture according to the organs or parts of the body most especially involved. The disease appears to be comparatively rare during early life and in only a minority of the cases are there lesions of the superficial tissues of the body. When this happens diagnosis during life becomes possible. The case about to be reported had superficial lesions in the form of a nodular erythema and during the earlier stages of the prolonged illness the vascular occlusion was sufficient to produce several areas of localized gangrene.

Rothstein and Welt (1933) reviewed the cases in children which have been reported up to 1932 . With two of their own cases these number twenty-three of a total of one hundred and ninety-five cases mentioned by them at all ages. The majority of the cases have been reported in the American and German literature. In this country Barnard and Burbury (1934) have reported the case of a child of eight years whose illness terminated fatally after a course of eight weeks and who showed extensive peripheral lesions of the nature of painful cyanosis of the extremities and gangrene. The present case is unusual in that recovery took place after a prolonged illness made up of a series of recrudescences separated by varying periods of comparative freedom from symptoms. The course of this patient's illness resembled that of the child described by Lindberg (1931). It is possible that this form of the disease, characterized by superficial erythematous nodules, has a more favourable prognosis.

\section{Case report}

Mary H., aged seven years, is the eldest of four children. The three other children and the parents are alive and well. The medical history of the family is uneventful. There is no history of rheumatic disease. The patient was quite well until July, 1935, when she developed headache and fever. She was seen 
by Dr. Cooke of Hunslet, Leeds, who found active tonsillitis. Nine days later she complained of generalized pains and there was redness and swelling of the left wrist. She was then admitted to St. James' Hospital, Leeds, as a case of acute rheumatism.

The whole illness lasted twenty-two months and comprised five phases of active illness of approximately five months, eight months, five weeks, three weeks and five weeks. The long phase of eight months was divided into two approximately equal parts by a brief interlude of three weeks during which the characteristic symptoms subsided and the temperature became normal. The child, however, was still listless and ill. The five phases of illness were roughly separated by quiescent intervals of eight weeks, six months, three weeks, and three weeks during which time the child was well and able to enjoy life.

The initial phase lasted from July 26, 1935, to September 4, 1935 . The onset as noted above had the clinical aspect of an acute rheumatism. On admission to St. James' Hospital the child was obviously ill. There was active tonsillitis with difficulty in opening the mouth suggesting peritonsillar abscess. There was also generalized pain, specially evident when an attempt was made to move the limbs passively. During the early days in hospital she developed colicky abdominal pain and there was tenderness and rigidity of the abdominal wall sufficiently pronounced to suggest the possibility of a septic peritonitis. The stool contained blood and mucus. The urine contained a trace of albumin. The temperature was $101^{\circ}-102^{\circ} \mathrm{F}$. and pulse $120-140$. The heart was not enlarged though its rate was rapid, and there were no bruits or pericardial friction. Ten days after admission there was oedema of the face and eyelids. By this time the illness had the aspect of a septic condition and the oedema suggested sinus infection. A month after the onset improvement began to show itself. The temperature became normal on September 4, and the symptoms subsided and she remained comfortable and appeared to be convalescent until November 5, when the second phase began. A throat swab taken during the early days was negative for B. diptheriae.

The second phase lasted from November 5, 1935, to the middle of July 1936. This phase also began with headache and sore throat. A patch of membrane appeared on the left tonsil and the throat swab was reported as positive for B. diptheriae. The child was then sent to the Seacroft Fever Hospital. The diagnosis was confirmed and she was shown to be Schick negative. No serum was given. The organism was classified as belonging to the intermediate type.

Within a few days of admission to Seacroft Hospital small red papules or nodes, slightly indurated to palpation, developed over both cheeks, the right eyelid, about the elbows and over the extensor surface of her knees. During the following weeks there were fresh crops of nodules over different parts of the body, such as the sacral region, the hands and wrist, the feet, the shoulders, the right groin and buttocks, over the front of trunk, and the right thigh. On February 27 there was a final outbreak of nodules over the knees, feet, elbows and forearms. The cycle of events in the development and subsidence of these nodules was as follows : each node was slightly raised, tender and gave the feeling of induration involving the tissues deeper than the skin. Around the nodes there were areas of spreading erythema which coalesced as the nodes aged. There was also deepening of colour to purple, producing a cyanotic appearance of the area involved. Subsequently there remained a more or less pigmented appearance giving a 'café-au-lait' effect which persisted for some 
weeks. During the early stages of the development of the erythematous nodes the appearance produced was not unlike that of erythema nodosum, but this appearance was quickly lost. The individual node was not thought to be so tender as that of erythema nodosum, although the area involved was generally hyperaesthetic, and this indeed was at times most pronounced, and with the pain in the limbs, especially with any movement, caused the child great discomfort. Coincident with the involvement of the looser tissues of the face there was local oedema. It was during this phase of illness that several small areas became gangrenous. This development was quite clearly a more advanced stage of the subcutaneous inflammatory process which was producing the lesions just described and which, with the exceptions to be mentioned, finally resolved without leaving permanent visible injury to the skin and underlying structures.

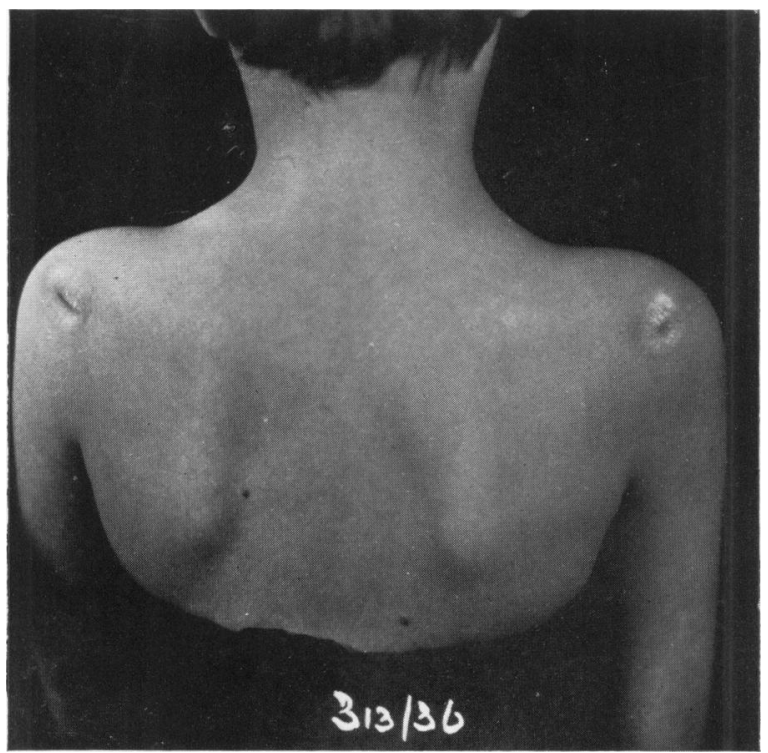

FIg. 1.-The symmetrical scars resulting from the two areas of superficial gangrene.

The points of local gangrene were as follows : two symmetrical areas behind the shoulders (fig. 1), which became black and crusted and the superficial tissue was finally shed with the formation of irregular whitish scars measuring approximately one-and-a-half inches across. Following a painful cyanotic swelling of the left index finger, the terminal phalanx became black and dead and finally separated, leaving the finger shortened by three-quarters of an inch (fig. 2). The end of the nose became blue, superficial gangrene took place and a small white indented scar resulted (fig. 3). A perforation of the nasal septum was discovered following brisk epistaxis.

The constitutional disturbance during this long phase of illness was severe. Great difficulty was met with in feeding her, and her appearance towards the end of the eight months was that of extreme marasmus. Listlessness and irritability were persistent throughout. A distressing symptom was obvious 


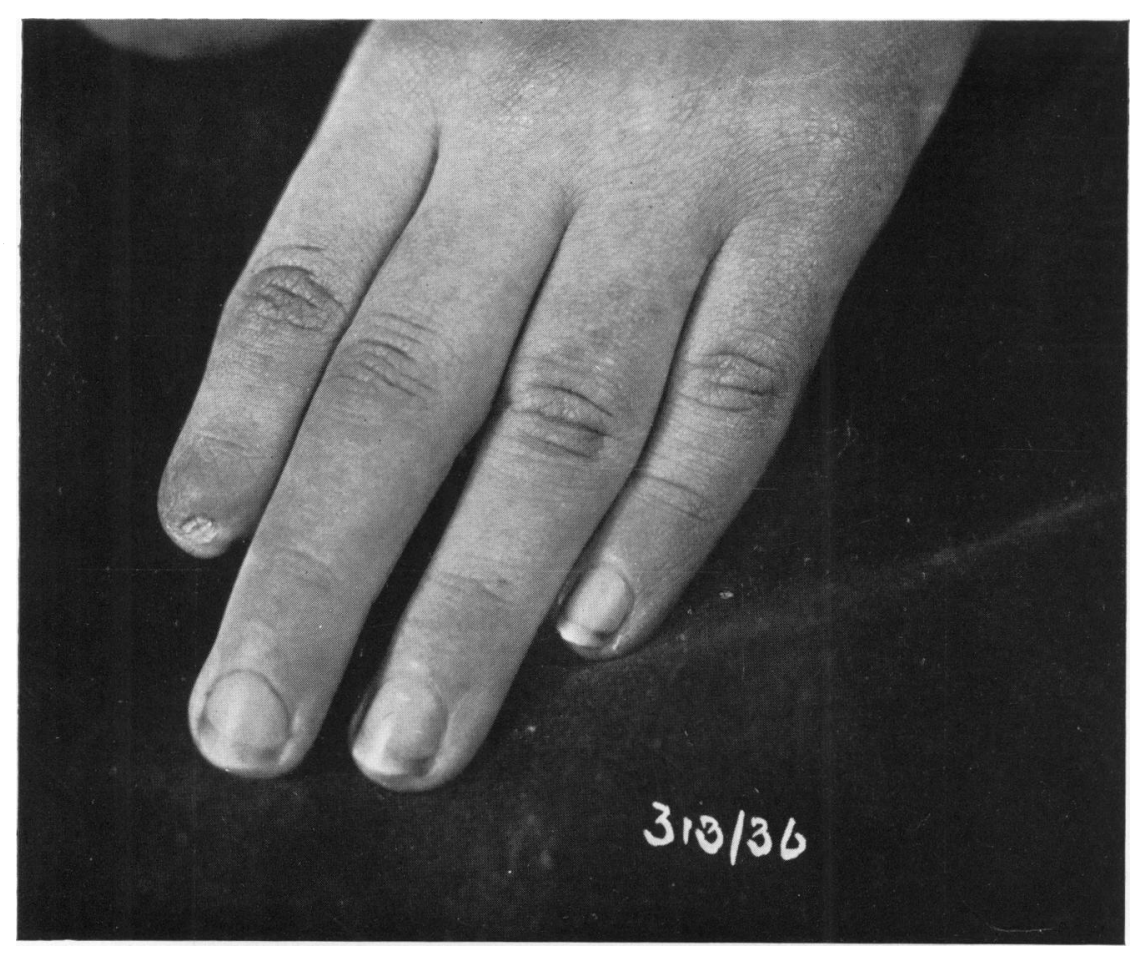

FIG. 2. The shortened index finger.

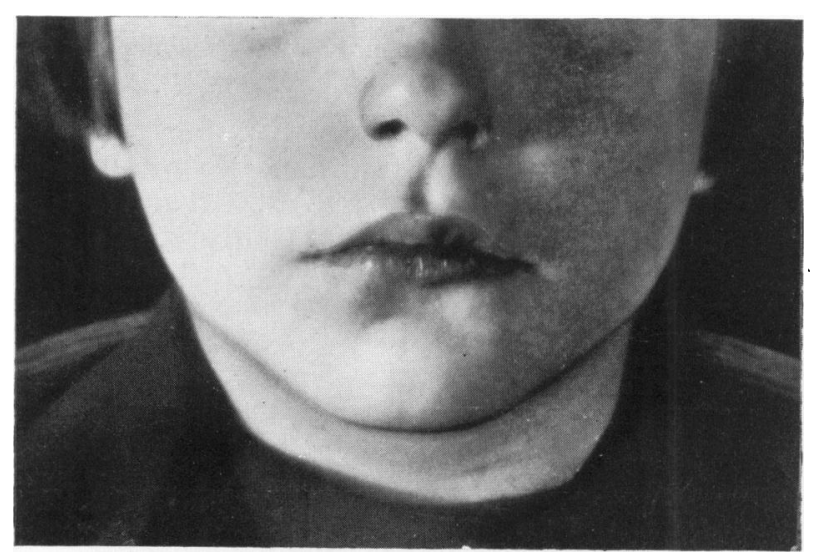

FIG. 3.-The depressed scar resulting from the superficial gangrene of tip of nose. 
discomfort when handled and when moved. Continuous flexion of the arms and legs was an interesting feature. There was almost continuous pyrexia during the whole period except for two intervals of four weeks and ten days during which the temperature was normal. From time to time there was swelling about several joints, but this was judged to be the result of the nodal erythematous formation about the joint rather than due to synovitis. The pulse rate was much increased throughout, and even during sleep remained about 120 . It was felt that the rate was not entirely explained by the rise in temperature. The heart sounds remained clear, and the rather loud short first sound suggested dilatation. At no time was there bruit or friction. The blood pressure was $80 \mathrm{~mm}$. Hg. systolic and $40 \mathrm{~mm}$. diastolic. Towards the end of the phase the child had a mild stomatitis which was troublesome for two or three weeks.

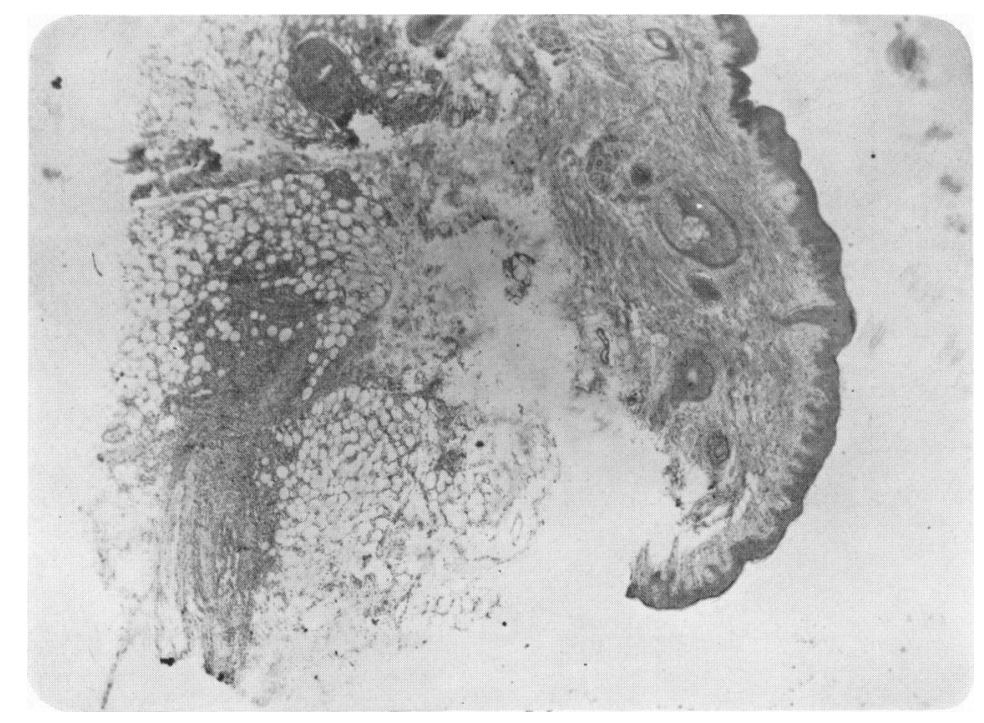

FIG. 4.

The child was considered convalescent towards the end of July and was then able to get up. Weight increased steadily. She was discharged from hospital at the end of September, her weight then being $50 \mathrm{lb}$. The first four months of the long phase of illness took place at Seacroft Hospital, the child being returned to St. James' Hospital on March 3 at the time when her active symptoms had subsided. While at Seacroft she was seen by Dr. John Ingram, Dermatologist at the Leeds General Infirmary, and he was the first to express the opinion that the child might be suffering from periarteritis nodosa.

The following are the chief examinations carried out during this period : March 26 : White cells 8,400 per c.mm., neutrophil polymorphs 85 per cent., eosinophils 0.3 per cent., mast cells 0.3 per cent., lymphocytes 10 per cent., large hyalines $2 \cdot 4$ per cent. Wassermann test : negative.

April 23 : White cells 6,500 per c.mm., sedimentation rate : 1 st hour, $140 \mathrm{~mm}$. ; 2nd hour, $147 \mathrm{~mm}$.; 4th hour, $150 \mathrm{~mm}$. 


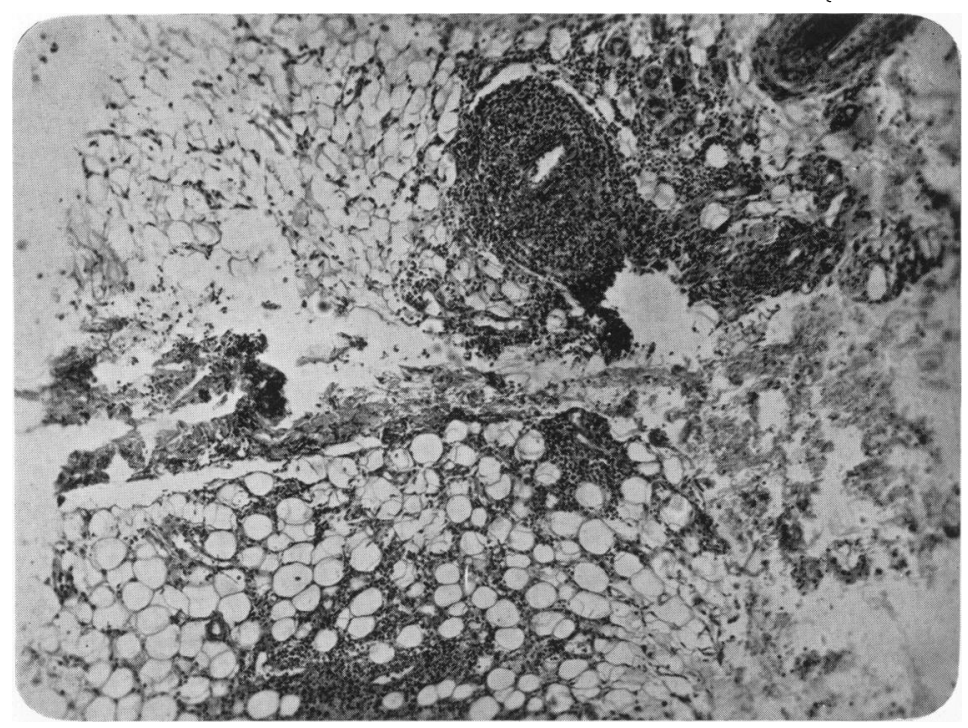

FIG. 5.

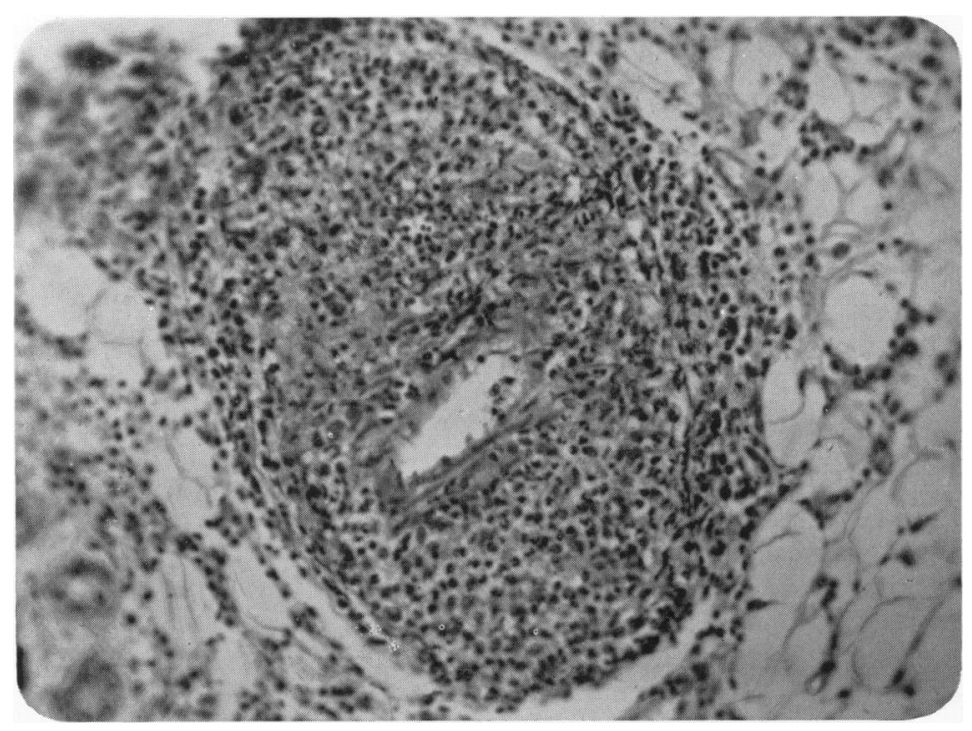

FIG. 6. 
Julyj29 : White cells 14,500 per c.mm., neutrophil polymorphs $51 \cdot 5$ per cent., eosinophils 6 per cent., mast cells 1 per cent., lymphocytes 34 per cent. large hyalines $7 \cdot 5$ per cent.

On April 2 a nodule from the arm was removed and the following is the report : One of the subcutaneous nodules was excised for biopsy. It measured $5 \mathrm{~cm}$. by $3 \mathrm{~cm}$. (fig. 4). Swelling was due to localized inflammation related to two small arteries in the subcutaneous tissue (fig. 5) and also involving the intervening fatty tissue. The appearances of both these arteries were similar. One vessel, $3 \mathrm{~mm}$. in diameter, was grossly destroyed by inflammation, so that only the single layer of endothelium forming the intima was recognizable (fig. 6). The internal elastic lamina was also intact. The wall of the vessel was widely infiltrated by cells of inflammatory type, the majority being polymorphonuclear leucocytes ; a proportion of these were eosinophilic. Fibrinoid degeneration was also apparent in the media.

The other vessel involved was approximately $7 \mathrm{~mm}$. by $3 \mathrm{~mm}$. and presented

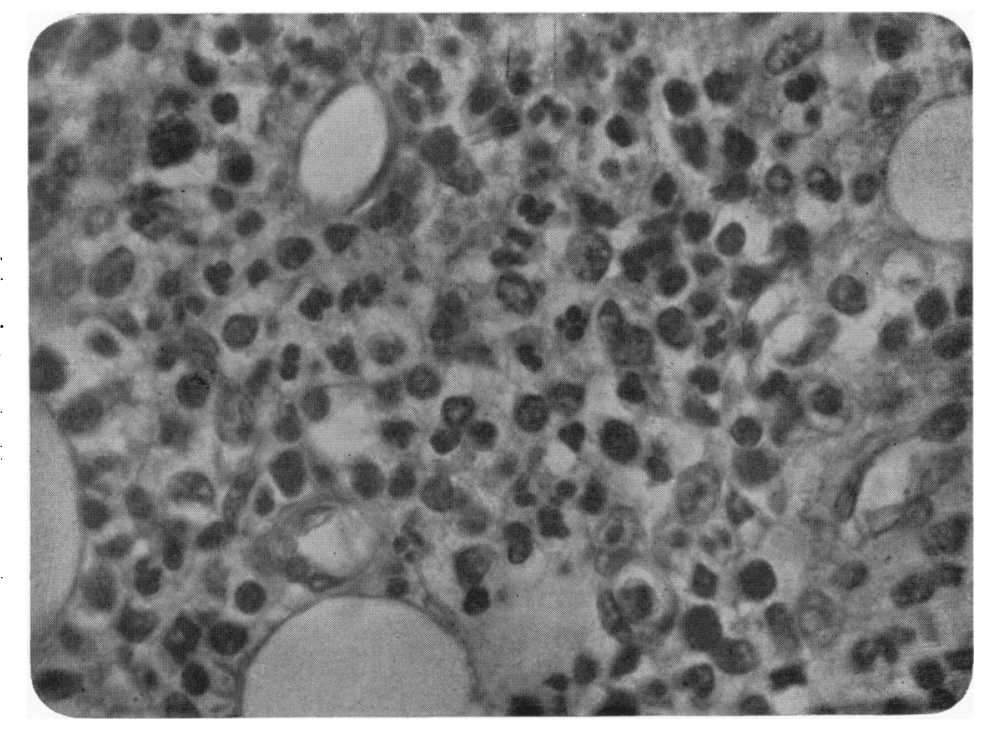

FIG. 7.

similar appearances, with the addition of thrombosis ; canalization of the clot had occurred. Eosinophilic infiltration in the neighbourhood of this vessel was particularly pronounced, accounting for approximately a third of the cells. There were a few plasma cells, and there was evidence of fibroblastic proliferation (fig. 7). These appearances were thought characteristic of periarteritis nodosa.

In the third phase the child remained perfectly well until December 16, 1936. Her feet then became swollen and painful and there was pain with movement of the hands. She was re-admitted to St. James' Hospital.

Her condition on admission was : temperature $101^{\circ} \mathrm{F}$., pulse 128 and respiration 26. The tonsils were injected and swollen. There was tenderness over legs, specially about the feet and ankles, which were slightly swollen. The arms were flexed and the right shoulder was fixed and painful. There was patchy erythema over face, cheeks and neck with nodules scattered unevenly over this 
area and over the arms, dorsum of hands and to a less extent over the trunk and legs. The degree of illness and prostration was not severe.

The nodules with their spreading erythema passed through the same stages of coalescing and tendency to deepen in colour as they aged. The pulse rate was again increased and ranged between 120 and 150. Even during sleep the pulse kept at 120. The general hyperaesthesia and pain in the limbs were again evident and the flexion at the proximal joints was repeated. A painful stomatitis was again troublesome, and on this occasion was much more severe and prolonged. There was no formation of membrane or obvious ulceration. Rather was the appearance one of acute swelling and congestion of the whole area of the mouth, accompanied by pronounced gingivitis of a painful character.

This phase lasted approximately five weeks. The temperature became normal by January 6 and the active and painful symptoms had disappeared by January 20.

The pathological investigations during this phase included : Blood examination : whites 22,900 , per c.mm., polymorphs 85 per cent., lymphocytes 11 per cent., eosinophils 1 per cent., myelocytes 2 per cent. Sedimentation rate : 1st hour, $32 \mathrm{~mm}$.; 2nd hour, $47 \mathrm{~mm}$. Blood culture negative. Throat swab : Staphylococci obtained on culture. Mouth swab : No spirochaete or fusiform bacilli seen.

There was an interval of three weeks during which the child remained comfortable and was able to sit up and take her food normally.

The fourth phase of illness began with repetition of the pyrexia and the development of nodal erythema over the arms and dorsum of the feet. On this occasion there was no general spread, nor was there tonsillar inflammation or stomatitis. There was, however, a recurrence of the pain in the limbs and flexion of the large joints. Within three weeks the child became free from active symptoms and remained well for three weeks.

The fifth and last phase was similar in its symptomatic presentation to the preceding one. It lasted, however, for five weeks and the nodal erythema was more widespread and the constitutional disturbance, while rather more severe, was not so intense as that experienced during the earlier phases.

Blood examination : reds $3,270,000$ per c.mm., C.I. 0.9 , Hb 60 per cent., whites 24,000 per c.mm., polymorphs 85 per cent., lymphocytes 14 per cent., eosinophils nil.

Sedimentation rate : 1st hour, $130 \mathrm{~mm}$.; 2nd hour, $141 \mathrm{~mm}$. During the convalescent period a further test was as follows : 1st hour, $13 \mathrm{~mm}$., 2nd hour, $37 \mathrm{~mm}$.

The child was discharged from hospital during the third week in July and has remained well since (September, 1937).

\section{Discussion}

Only a small minority of the cases of periarteritis nodosa so far reported resemble this case. A diagnosis is rarely possible during life because so few patients have superficial lesions. In the majority the clinical picture is bizarre and most variable, and depends upon the disturbance in function of the organs involved. This is due, in the main, to the interference with the blood supply brought about by the arterial occlusion from intimal thickening and thrombosis, and in some cases by the resultant gangrene. The clinical picture may simulate closely nephritis (haematuria, albuminuria, increased blood pressure), acute abdominal disease (cramp, vomiting, diarrhoea, melaena), myositis (muscular 
pains and tenderness), cerebral disease (hemiplegia from rupture of aneurysm), cardiac disease (quickened pulse, coronary occlusion), acute rheumatism (pain, tenderness, pyrexia), purpura haemorrhagica (subcutaneous haemorrhage, melaena), arterio-sclerosis (widespread vascular scarring and occlusion), or may take the form of this case.

The onset of the patient's illness suggested a rheumatic infection, although the acute abdominal symptoms and the blood in the stools during the early days and the oedema of the face and eyelids at the end of the first fortnight seemed to discount this provisional diagnosis. It was then thought that she was suffering from some septic infection and the facial oedema suggested sinus trouble. In the light, however, of the symptoms reported by other observers it is possible that the initial facial oedema was the result of the periarteritis nodosa of the subcutaneous vessels, and that the abdominal symptoms indicated like involvement of branches of the mesenteric vessels.

The diagnosis in the majority of reported cases has rested on the autopsy findings. The feature common to all these cases was widespread destructive arteritis of a patchy rather than diffuse type of sufficient severity to cause patchy necrosis of the vessel wall, occlusion and thrombosis. The nodular formation has been due to the massive local cellular infiltration of the adventitia or in some cases to the formation of multiple small aneurysms. These striking pathological features have lead to the belief that periarteritis nodosa is a disease caused by a specific etiological agent. The question, however, has been frequently raised if it is not possible that some of the reported cases are examples of arterial damage produced by different agents, and not necessarily by the specific agent, which, in the case of periarteritis nodosa is claimed to be a filtrable virus.

The Wassermann reaction is rarely positive. A positive reaction was observed by Bernstein (1935), in whose patient periarteritis nodosa was proved by biopsy of muscle tissue. Ophüls (1923), who discussed this fully, points out how closely some of the arterial lesions copy those of syphilis. The treponema pallidum has been looked for in the acute severe lesions of the disease and they have never been found. The pronounced polymorphonuclear infiltration in periarteritis nodosa, a striking feature, seems also to discount a syphilitic infection.

The interesting and not infrequent association of periarteritis nodosa with acute rheumatic fever has been noted on several occasions. Ophüls (1923) refers to this, but expresses the opinion that the two processes are different clinically and pathologically and are to be easily differentiated. Rothstein and Welt (1933) described a boy of seven years who at post-mortem had a subacute verrucous rheumatic endocarditis with typical Aschoff nodes in the heart muscle. Widespread lesions of periarteritis nodosa were also present. Friedberg and Gross (1934), in reviewing eight cases of the disease, found Aschoff nodes in the myocardium of four of the cases. One of the cases had suffered from acute chorea and at post-mortem there were found acute myocardial and endocardial rheumatic lesions associated with widespread lesions of periarteritis nodosa. These lesions involved the arteries of the lungs and 
kidneys and the external iliac and the coronary arteries. During life the clinical picture had been that of an acute rheumatic affection. They also refer to several other cases in which the association was revealed at post-mortem. In submitting that the two pathological processes can be easily differentiated, they give as one of the points of differentiation the widespread outlying distribution of the lesions of periarteritis nodosa and the close relationship of the rheumatic lesions to the cardiac area. Middleton and McCarter (1935) have also referred to this association in the two hundred cases reviewed by them.

Coates and Coombs (1923) called attention to the widespread distribution of the rheumatic nodule, its formation round a central small vascular lesion and its identity in all respects with the Aschoff node of the heart muscle and elsewhere. Bernard Shaw (1929) reported his post-mortem findings in a girl fifteen years of age whose death had been caused by acute rheumatic fever and showed widespread distribution of the rheumatic lesions, these being found in the carotids, subclavian and renal arteries, superior vena cava and in the muscles, and especially in and about their junction with the tendons. No lesions, however, were found in the vessels of the liver, kidneys, spleen, and lungs. Frazer (1934) also draws attention to the widespread nature of the rheumatic lesions and specially refers to the frequency of coronary endarteritis in acute rheumatism.

Notwithstanding the evidence that the lesions of acute rheumatism are undoubtedly widespread, there can be little doubt that the two types of vascular lesions are different and can be distinguished macroscopically and microscopically.

Von Glahn and Pappenheimer (1926), from a study of forty-seven consecutive cases of rheumatic heart disease, found in ten of the cases widespread rheumatic vascular lesions involving arteries of the lungs, aortic valve, kidney, ovary, testis, pancreas and perirenal and periadrenal adipose tissue. In two of the cases the pulmonary arteries and those of the kidney were extensively damaged. Their microscopic study revealed thickening of the vessels with reduction of the lumen and with a complete absence of thrombosis. They describe a fibrinous infiltration of the vessel usually limited by the internal elastic lamella, and necrosis of the cellular constituents of the vessel wall. External to these necrotic areas there was a distinctive cellular tissue composed of a loose fibrillar stroma partly fibrinous and containing nuclei and showing infiltration with scanty lymphoid and plasma cells, and occasional eosinophils, and a distinctive feature was the formation within this inflamed area of new blood channels. Von Glahn and Pappenheimer discuss the relationship of these lesions, which they considered to be typical of rheumatism, with those of periarteritis nodosa, and express the opinion that differentiation is possible and they summarize the distinguishing features as follows : $(a)$ thrombosis is common in periarteritis nodosa and absent in the rheumatic lesions; (b) periarteritis nodosa attacks arteries of medium calibre while those affected by rheumatism are usually of the small type and include the arterioles and sinusoidal capillaries ; $(c)$ nodular formation in periarteritis nodosa is macroscopic as well as microscopic, while in rheumatism there is no nodular vascular develop- 
ment and the lesions are invariably microscopic ; $(d)$ there is absence of infarction, and haemorrhage from rupture in the rheumatic lesions ; and $(e)$ conspicuous eosinophilic infiltration is present in most periarteritis nodosa lesions while in the rheumatic lesion eosinophilia is minimal.

Clinically there can be no doubt at all that the lesions of periarteritis nodosa produce results quite different from anything seen in a severe case of rheumatism. The arteritis is much more severe and profound and the development of gangrene, as in this case and particularly in the one reported by Barnard and Burbury (1934), should be sufficient in itself to show that the pathological process is on quite a different scale from that of acute rheumatism, in which the vascular lesions are not associated with thrombus formation ; nor is it possible that the lesions of periarteritis nodosa may sometimes simulate those of acute rheumatism, because in cases in which the association has been reported the typical Aschoff node has been found in close proximity to the typical lesions of periarteritis nodosa.

The microscopic appearance of the periarteritis nodosa lesion has been referred to by many observers. The media seems to be the part of the arterial wall which bears the brunt of initial damage, and at this point fibrinous degeneration and actual necrosis of the muscle takes place with damage to the elastica followed by massive infiltration of the adventitia with polymorphs, lymphocytes, plasma cells and, in some cases, eosinophils. This primary damage to the media leads to proliferation of the intima, and this produces occlusion, thrombosis and sometimes destruction which finally may result in haemorrhage or aneurysmal formation, and in some cases the local vascular occlusion is sufficiently severe and concentrated to produce local gangrene. The presence of eosinophils in the neighbourhood of an arterial lesion has been drawn attention to by several reporters (Barnard and Burbury, Rothstein and Welt, Middleton and McCarter, Friedberg and Gross), and it has been suggested that the eosinophilic involvement is an evidence of an allergic factor, and possibly it is here that the relationship of rheumatism and periarteritis nodosa exists. It is possible that a primary rheumatic infection in certain cases acts as the sensitizing factor and prepares the way for the destructive attack by the infective agent of periarteritis nodosa.

If it is agreed that syphilis is not an etiological factor and that the lesions of rheumatism and periarteritis nodosa are distinguishable both in early appearance and final results, it is difficult to suggest any other known infective agent which could account for an arteritis of so destructive a grade, and it is for this reason that some observers have claimed for this disease a specific etiological agent and probably a filtrable virus. Von Haum (1919) and Harris and Friedricks (1922) claim to have produced typical lesions, the former in guinea-pigs and the latter in rabbits, by inoculation of filtrates made from typical nodules taken at post-mortem. Ophüls criticizes this evidence, which he submits is unconvincing. He believes that the vascular damage may quite likely be produced by different agents under suitable conditions, and it would seem that he is of the opinion that the rheumatic infection, which he agrees is often associated with that of periarteritis nodosa, prepares the way for the latter, and 
no doubt Ophüls' conception of the disease is that of an allergic manifestation. Carling and Hicks (1923) tried to repeat these animal experiments, but failed to introduce the disease into guinea-pigs. Gruber (1926) is of the opinion that they are not specific lesions and may be produced by several agents. Spiro (1919) believes that the lesions differ only quantitatively from those encountered in many infective diseases, e.g. measles, scarlatina, diphtheria.

The duration of the illness in twenty-three children, with one exception, was less than a year, and the majority died within six months of the onset (Rothstein and Welt). Lindberg (1931) reported a case in which the child, aged fifteen years, recovered after an illness of four-and-a-half years' duration. The circumstances of this illness resemble those of this patient.

Half the patients were adults of from thirty to fifty years of age and the ages in a series of one hundred and ninety-five ranged from nine months to seventyeight years (Rothstein and Welt).

The main clinical features of the twenty-three children in the cases reported by Rothstein and Welt, in their order of approximate frequency were : pyrexia (17), increased pulse rate (12), abdominal pain (12), leucocytosis (12), prostration and weakness (11), muscle and joint pains (9), convulsions (11), skin rashes (8), oedema (8), anaemia (8), increased blood pressure (7), sore throat (6), and in only one case were there any subcutaneous nodules (Lindberg). In only two cases in addition to that under discussion was the diagnosis made by biopsy (Lindberg and Rothstein and Welt).

Three further instances of the disease in children have been described since 1933. That of Barnard and Burby (1934) was notable on account of the severity of the vascular lesions resulting in extensive gangrene of the limbs.

Friedberg and Gross (1934) reported a case, a child ten years old, but it is open to question if this was not an instance of acute rheumatic carditis with widespread vascular lesions. In the case reported by Krahulik, Rosenthal and Loughlin (1935) the child had superficial lesions of the ankle and the illness terminated fatally. The post-mortem picture was that of a healed rheumatic endocarditis, with fluid in the serous cavities and extensive vascular lesions in kidney, liver and spleen. No Aschoff nodes were present.

The superficial manifestations of the disease appear less common than those involving the organs and deeper structures. These skin lesions show considerable variation from case to case. The nodal erythema in this patient is thought a characteristic superficial manifestation of the disease ; the child described by Barnard and Burbury had no nodal erythema, but developed an increasing cyanosis and gangrene of the extremities. Debré and others (1928) refer to skin lesions consisting of polymorph-papulo-vesicular eruption of dark red-violet papules and vesicles with sero-haemorrhagic contents and patchy ecchymosis of limbs, mouth and nares, and also they mention erythematous rashes, trophic ulcers, subcutaneous nodules, petechiae, yet in none of these patients were the skin lesions dominant, nor were they the only manifestation of the disease.

In reviewing the numerous cases which have been reported in the literature 
the impression that is produced is one of reasonable doubt as to how far it may be accepted that these arterial lesions constitute a single disease entity called periarteritis nodosa. This doubt especially arises, in some of those cases in which the acute rheumatic lesions has been reported to be associated with the lesion of periarteritis nodosa. In this country no such association has, so far as is known, been reported. On the other hand Bernard Shaw and Fraser have drawn attention to the widespread distribution of the rheumatic vascular lesion in the acute cases, and much therefore will depend upon the microscopic interpretation of the lesions present.

The point of differentiation summarized by Von Glahn and Pappenheimer, notably the presence or absence of thrombosis, are important, but possibly not conclusive. There can be, of course, no doubt at all that in the unequivocal cases of periarteritis nodosa, as for example that of Barnard and Burbury, there was a degree of arterial damage quite unlike anything seen in rheumatism and produced by some agent whose destructive action is unlike, certainly in its intensity, any other known metabolic or infective agent. The decision as to whether this destructive agent is a specific one, or whether given the suitable conditions, an arteritis of such magnitude can result from sensitization and allergic reaction by the inter-action of various agents must be left to the future to decide, and it is because of these interesting problems that arise in connection with this disease that this patient has been described.

Thanks are due to Dr. Cyril Polson, Pathologist at St. James' Hospital, for the pathological and blood reports and for the micro-photographs, and also for his interest in the case, and to Dr. E. C. Benn, Medical Superintendent at Seacroft Hospital, for allowing access to the notes ; and to Dr. Hester Woodcock, who drew attention to the unusual course of the illness whilst the child was under her care at Seacroft and who made detailed notes of the case.

\section{REFERENCES}

Barnard, W. G., and Burbury, W. M. (1934). J. Path. Bact., 39, 285.

Bernstein, A. (1935). Amer. J. med. Sci., 190, 317.

Carling, E. R., and Hicks, J. A. B. (1923). Lancet, 1, 1001.

Coates, V., and Coombs, C. F. (1926). Arch. Dis. Childh., 1, 183.

Debré, R., Leroux, R., Delong, M., and Gauthier-Villars, P. (1928a). Bull. Mém. Soc. méd. Hop. Paris, 52, 165. (1928b). Arch. Med. Enf., 31, 325.

Fraser, A. D. (1934). Arch. Dis. Childh., 9, 267.

Friedberg, C. K., and Gross, L. (1934). Arch. int. Med., 34, 170.

Gruber, G. B. (1923). Virchow's Arch. 255, 123. (1925). Ibid., 258, 441.

Harris, W. H., and Friedricks, A. V. (1922). J. exp. Med., 36, 219.

Krahulik, L., Rosenthal, M., and Loughlin, E. H. (1935). Amer. J. med. Sci., 190, 308.

Lindberg, K. (1931). Acta med. scand., 76, 183.

Middleton, W. S., and McCarter, J. C. (1935). Amer. J. med. Sci., 190, 291. 
Ophüls, W. (1923). Arch. int. Med., 32, 870.

Rothstein, J. L., and Welt, S. (1933). Amer. J. Dis. Childh., 45, 1277.

Shaw, A. F. B. (1929). Arch. Dis. Childh., 4, 155.

Spiro, P. (1919-20). Virchow's Arch., Berlin, 227, 1.

Von Glahn, W. C., and Pappenheimer, A. M. (1926). Amer. J. Path., 2, 235.

Von Haum, F. (1919-20). Virchow's Arch., 127, 90. 